\title{
Selective Estrogen Receptor Modulators Regulate Dendritic Spine Plasticity in the Hippocampus of Male Rats
}

\author{
Ignacio González-Burgos, ${ }^{1,2}$ Martha C. Rivera-Cervantes, ${ }^{2}$ Dulce A. Velázquez-Zamora, ${ }^{1,2}$ \\ Alfredo Feria-Velasco, ${ }^{2}$ and Luis Miguel Garcia-Segura ${ }^{3}$
}

${ }^{1}$ Centro de Investigación Biomédica de Occidente, Guadalajara, Jalisco 44340, Mexico

${ }^{2}$ CUCBA, Universidad de Guadalajara, Guadalajara, Jalisco 45100, Mexico

${ }^{3}$ Instituto Cajal, CSIC, 28002 Madrid, Spain

Correspondence should be addressed to Luis Miguel Garcia-Segura, lmgs@cajal.csic.es

Received 19 July 2011; Accepted 12 August 2011

Academic Editor: Irina Nikonenko

Copyright (c) 2012 Ignacio González-Burgos et al. This is an open access article distributed under the Creative Commons Attribution License, which permits unrestricted use, distribution, and reproduction in any medium, provided the original work is properly cited.

\begin{abstract}
Some selective estrogen receptor modulators, such as raloxifene and tamoxifen, are neuroprotective and reduce brain inflammation in several experimental models of neurodegeneration. In addition, raloxifene and tamoxifen counteract cognitive deficits caused by gonadal hormone deprivation in male rats. In this study, we have explored whether raloxifene and tamoxifen may regulate the number and geometry of dendritic spines in CA1 pyramidal neurons of the rat hippocampus. Young adult male rats were injected with raloxifene $(1 \mathrm{mg} / \mathrm{kg})$, tamoxifen $(1 \mathrm{mg} / \mathrm{kg})$, or vehicle and killed $24 \mathrm{~h}$ after the injection. Animals treated with raloxifene or tamoxifen showed an increased numerical density of dendritic spines in CA1 pyramidal neurons compared to animals treated with vehicle. Raloxifene and tamoxifen had also specific effects in the morphology of spines. These findings suggest that raloxifene and tamoxifen may influence the processing of information by hippocampal pyramidal neurons by affecting the number and shape of dendritic spines.
\end{abstract}

\section{Introduction}

Selective estrogen receptor modulators (SERMs) either synthetic or natural, such as phytoestrogens, are candidates for the treatment or the prevention of cognitive and affective disorders in men and women [1-5]. Several studies have shown that some synthetic SERMs, such as tamoxifen, raloxifene, or bazedoxifene [6-29], some nonfeminizing estrogens [3034], and some natural SERMs, such as genistein [35, 36], are neuroprotective in vitro and in vivo. The neuroprotective effects of SERMs are associated with a decrease in the activation of microglia and astroglia and a reduction in brain inflammation [37-43]. In addition, some SERMs have shown to induce neuritic outgrowth in vitro $[44,45]$, suggesting that these molecules may also affect synaptic connectivity in vivo. Indeed, ERs are involved in the regulation of dendritic spines in the hippocampus of female animals in vivo [46-51], where tamoxifen regulates synaptophysin expression [52]. SERMs are also able to regulate cholinergic, serotonergic, and dopaminergic neurotransmission in female animals [53-56].
However, the effects of SERMs on synaptic connectivity in males have not been adequately explored. Nevertheless, previous studies have shown that SERMs such as raloxifene and tamoxifen are able to counteract hippocampus-dependent cognitive deficits caused by androgen deprivation in male rats [57]. In addition, raloxifene reduces working memory deficits in male rats after traumatic brain injury [20].

To further characterize the mechanisms of action of SERMs in the male brain, we have assessed in this study the effects of tamoxifen and raloxifene on the number and geometry of dendritic spines in CA1 pyramidal neurons of the rat hippocampus.

\section{Material and Methods}

2.1. Animals and Treatments. Sprague-Dawley adult male rats were maintained under regular $12 \mathrm{~h}$ light-dark cycles (lights on: 07:00-19:00 h) and controlled environmental humidity $(45-50 \%)$ and temperature $\left(22 \pm 2^{\circ} \mathrm{C}\right)$. Animals had free access to food and water. All the experimental procedures 


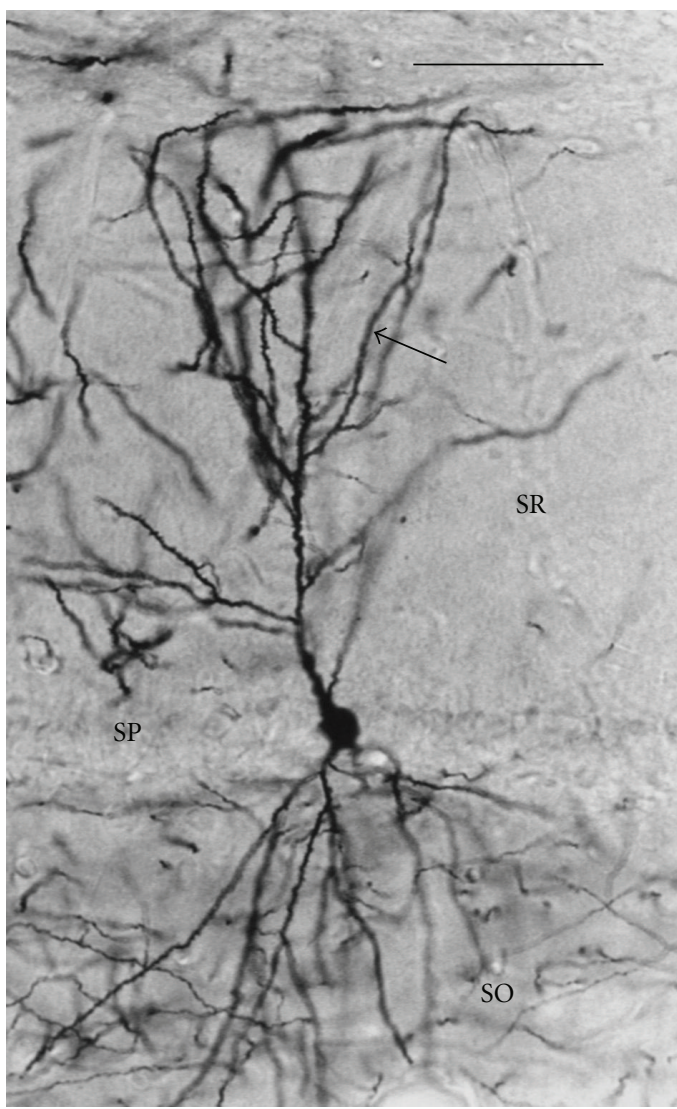

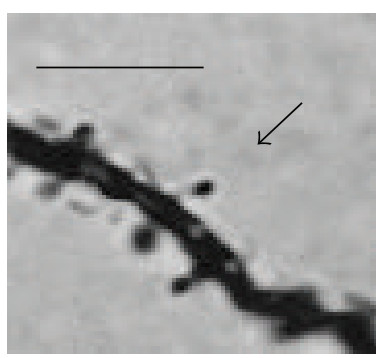

(a)

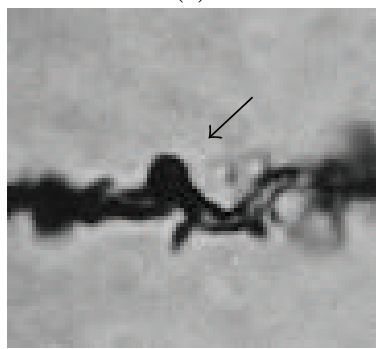

(c)

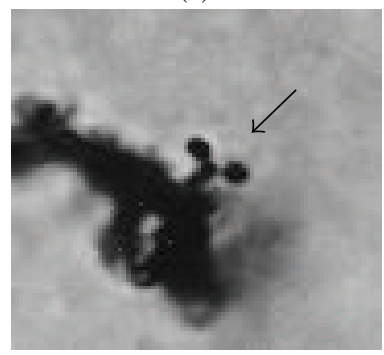

(e)

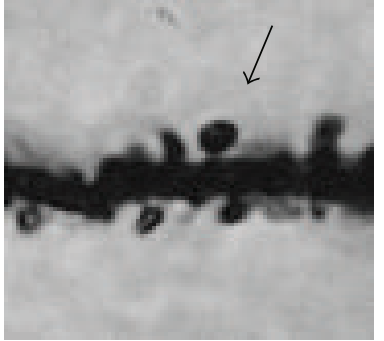

(b)

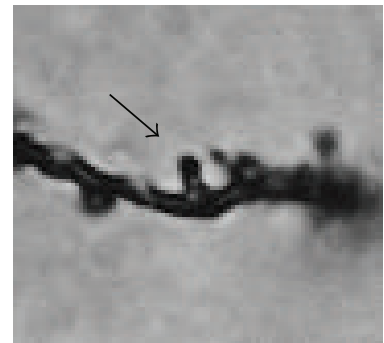

(d)

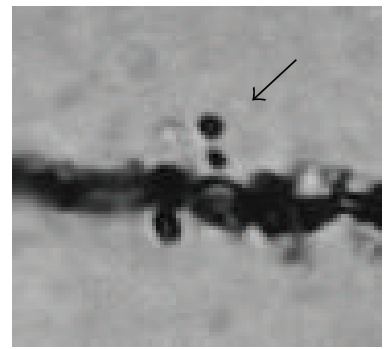

(f)

FIGURE 1: Examples of dendritic spines stained with the Golgi method. Left panel: photomicrograph of a CA1 pyramidal neuron impregnated with a modification of the Golgi method. Spines studied in the present work were counted in a segment $50 \mu \mathrm{m}$ in length of a secondary dendrite (arrow) protruding from its parent apical dendrite. SO: stratum oriens; SP: stratum pyramidale; SR: stratum radiatum. Scale bar = $100 \mu \mathrm{m}$. In the right panels, photomicrographs show representative examples of thin (a), mushroom (b), stubby (c), wide (d), branched (e), and double (f) spines (arrows). Scale bar $=5 \mu \mathrm{m}$.

were conducted to minimize pain or discomfort in the animals and performed in accordance with the NIH guide for Care and Use of Laboratory Animals (NIH Publications no. 80-23, 1996 revised). Protocols were approved by our institutional animal care committee.

At the age of three months, animals were injected with raloxifene $(1 \mathrm{mg} / \mathrm{kg} ; n=6)$, tamoxifen $(1 \mathrm{mg} / \mathrm{kg} ; n=6)$, or vehicle $(20 \mathrm{mg} / \mathrm{mL}$ DMSO diluted $3 \%$ in saline solution; $n=6$ ). Animals were killed $24 \mathrm{~h}$ after the injection.

2.2. Golgi Studies. Animals were anesthetized with $30 \mathrm{mg} / \mathrm{kg}$ intramuscular ketamine and $50 \mathrm{mg} / \mathrm{kg}$ i.p. sodium pentobarbital. Then, animals were perfused intracardially with $100 \mathrm{~mL}$ of a washing phosphate-buffered solution ( $\mathrm{pH}$ 7.4; $0.01 \mathrm{M}$ ) containing $1000 \mathrm{IU} / \mathrm{L}$ of sodium heparin and $1 \mathrm{~g} / \mathrm{L}$ of procaine hydrochloride. Then, $200 \mathrm{~mL}$ of a fixing phosphatebuffered $4 \%$ formaldehyde solution was perfused. Both solutions flowed at a rate of $11.5 \mathrm{~mL} / \mathrm{min}$. Each brain remained for at least $48 \mathrm{~h}$ in $100 \mathrm{~mL}$ of a fresh fixing solution.

The bilateral dorsal hippocampi were dissected out and impregnated using a modification of the Golgi method [58]. Several coronal slices $100 \mu \mathrm{m}$ thick were mounted on one slide per animal. Spine numerical density and the proportion of thin, mushroom, stubby, wide, branched, and double spines [59-61] were assessed in CA1 pyramidal neurons. Spines were counted in one $50 \mu \mathrm{m}$ segment per cell, located in the middle of one of the secondary dendrites that protrude from the apical dendrite (Figure 1). Six CA1 pyramidal neurons were studied per animal. The total number of spines counted was 5,796 in the animals treated with vehicle: 9,295 in the animals treated with raloxifene and 9,180 in the animals treated with tamoxifen.

2.3. Statistical Analysis. The one-way ANOVA and Tukey post hoc test were used for statistical comparisons of data from spine numerical density. In addition, one-way ANOVA and Bonferroni correction post hoc test were used for statistical comparisons of the proportion of the different types of spines. The $n$ used for statistical analysis was the number of animals ( $n=6$, per experimental group).

\section{Results}

Raloxifene and tamoxifen increased significantly the total numerical density of dendritic spines compared to control animals (Table 1). Both SERMs increased the numerical 
TABLE 1: Numerical density of dendritic spines in hippocampal CA1 pyramidal neurons of male rats 24 hours after the treatment with vehicle, raloxifene, or tamoxifen.

\begin{tabular}{lccc}
\hline & Vehicle & Raloxifene & Tamoxifen \\
\hline Total spines & $161.0 \pm 5.0$ & $258.2 \pm 3.0^{\mathrm{a}}$ & $255.0 \pm 4.0^{\mathrm{b}}$ \\
Thin & $74.8 \pm 2.8$ & $89.6 \pm 3.8^{\mathrm{a}}$ & $78.0 \pm 3.6^{\mathrm{c}}$ \\
Mushroom & $50.4 \pm 1.8$ & $84.6 \pm 3.2^{\mathrm{a}}$ & $92.8 \pm 1.6^{\mathrm{bc}}$ \\
Stubby & $28.6 \pm 1.4$ & $65.8 \pm 1.8^{\mathrm{a}}$ & $71.0 \pm 2.2^{\mathrm{b}}$ \\
Wide & $6.2 \pm 0.6$ & $15.6 \pm 1.0^{\mathrm{a}}$ & $11.8 \pm 1.2^{\mathrm{bc}}$ \\
Branched & $0.4 \pm 0.1$ & $0.6 \pm 0.2$ & $0.6 \pm 0.1$ \\
Double & $0.1 \pm 0.04$ & $0.04 \pm 0.04$ & $0.4 \pm 0.1$ \\
\hline
\end{tabular}

Data represent mean \pm SEM of the number of dendritic spines per $100 \mu \mathrm{m}$ dendritic segment from 6 animals in each experimental group. ${ }^{\mathrm{a}-\mathrm{c}}$ Significant differences, $P<0.05$; ${ }^{\mathrm{a}}$ raloxifene versus Vehicle; ${ }^{\mathrm{b}}$ tamoxifen versus. Vehicle; ${ }^{c}$ tamoxifen versus Raloxifene.

TABle 2: Proportion (\%) of the different types of dendritic spines in hippocampal CA1 pyramidal neurons 24 hours after the treatment with vehicle, raloxifene, or tamoxifen.

\begin{tabular}{lccc}
\hline & Vehicle & Raloxifene & Tamoxifen \\
\hline Thin & 46.4 & $34.7^{\mathrm{a}}$ & $30.5^{\mathrm{b}}$ \\
Mushroom & 31.3 & $32.7^{\mathrm{a}}$ & $36.3^{\mathrm{bc}}$ \\
Stubby & 17.7 & $25.4^{\mathrm{a}}$ & $27.8^{\mathrm{b}}$ \\
Wide & 3.8 & $6.0^{\mathrm{a}}$ & 4.6 \\
Branched & 0.2 & 0.2 & 0.2 \\
Double & 0.07 & 0.01 & 0.1 \\
\hline
\end{tabular}

Data represent means from 6 animals in each experimental group. ${ }^{\mathrm{a}-\mathrm{c}}$ Significant differences, $P<0.05$; ${ }^{\mathrm{a}}$ raloxifene versus Vehicle; ${ }^{\mathrm{b}}$ tamoxifen versus Vehicle; ${ }^{C}$ tamoxifen versus raloxifene.

density of mushroom, stubby, and wide spines (Table 1). In addition, raloxifene increased the numerical density of thin spines (Table 1). Numerical density of mushroom spines was greater in tamoxifen-treated rats than in raloxifenetreated animals. In contrast, thin and wide spines were less numerous in the tamoxifen group than in raloxifene-treated animals (Table 1).

The experimental treatments also resulted in changes in the proportion of different spine morphologies. The proportion of thin spines was reduced in the animals treated with raloxifene. Furthermore, raloxifene increased the proportion of stubby and wide spines and did not significantly affect the proportion of mushroom, branched and double spines (Table 2).

As observed for raloxifene, the proportion of thin spines was also reduced in the animals treated with tamoxifen. In contrast, mushroom and stubby spines were seen in greater proportion in animals treated with tamoxifen than in control animals. Tamoxifen had no significant effects in the proportion of wide, branched, and double spines (Table 2). The animals treated with tamoxifen showed a higher proportion of mushroom spines than those treated with raloxifene (Table 2).

\section{Discussion}

Our present findings indicate that some SERMs, such as raloxifene and tamoxifen, affect the number of dendritic spines in male rats. This action of SERMs may affect the processing of novel information used in memory formation [62].

In addition to increase the numerical density of spines, raloxifene and tamoxifen also affected spine geometry. Both SERMs increased the numerical density of stubby, mushroom, and wide spines. In addition, raloxifene increased the number of thin spines. However, both SERMs reduced the proportion of thin dendritic spines. Dendritic spine morphology affects the diffusion and compartmentalization of membrane-associated proteins [63] and the expression of AMPA receptors [64-67]. In particular, the length of the spine neck seems to be a key regulator of spinodendritic Ca2+ signaling [68-72] and of the transmission of membrane potentials [73]. In consequence, the geometry of dendritic spines may influence the processing of synaptic impulses [74-79]. Our findings suggest, therefore, that raloxifene and tamoxifen, decreasing the proportion of thin dendritic spines, may influence the processing of information by hippocampal pyramidal neurons. In addition, the action of raloxifene and tamoxifen presents some differences that may have functional significance. Tamoxifen, but not raloxifene, increased the proportion of mushroom spines. Thus, the animals treated with tamoxifen had an increased numerical density and proportion of mushroom spines compared to animals treated with raloxifene. Mushroom spines may be involved in the management of previously acquired information since they have larger postsynaptic densities [80] and express higher levels of AMPA receptors [64-67]. Therefore, the synapses on mushroom spines are functionally stronger [78] and it has been suggested that these spines would sustain memory storage [78, 81, 82].

The induction of plastic changes in dendritic spines by raloxifene and tamoxifen may be linked with the precognitive effects of these molecules in male rats [20,57]. However, the possible impact of raloxifene and tamoxifen on cognitive decline in men remains to be adequately explored, in particular in association with neurodegenerative diseases. For instance, both SERMs increase the levels of luteinizing hormone (LH) in men [83] and it has been proposed that elevated levels of LH may contribute to Alzheimer's disease pathogenesis [84]. Indeed, leuprolide acetate, a GnRH agonist that lower serum levels of $\mathrm{LH}$, has been shown to improve cognitive performance and decrease amyloid$\beta$ deposition in a mouse transgenic model of Alzheimer's disease [85].

\section{Conclusions}

The findings of this study indicate that raloxifene and tamoxifen, two SERMs currently used in clinical treatments, promote an increase in the numerical density of dendritic spines and changes in spine geometry in the hippocampus of male rats. These findings, together with the regulation exerted by tamoxifen and raloxifene on hippocampusdependent cognitive function in male rats [57], suggest that 
SERMs may influence the processing of information by male hippocampal pyramidal neurons by affecting the number and shape of dendritic spines.

\section{Acknowledgments}

This work was supported by the Coordinación de Investigación en Salud, IMSS (FIS/IMSS/PROT/G10/821), Universidad de Guadalajara (U de G, P3e), México, and Ministerio de Ciencia e Innovación, Madrid, Spain (BFU2008-02950C03-01).

\section{References}

[1] R. D. Brinton, "Requirements of a brain selective estrogen: advances and remaining challenges for developing a NeuroSERM," Journal of Alzheimer's Disease, vol. 6, supplement, pp. S27-S35, 2004.

[2] F. Bernardi, N. Pluchino, M. Stomati, M. Pieri, and A. R. Genazzani, "CNS: sex steroids and SERMs," Annals of the New York Academy of Sciences, vol. 997, pp. 378-388, 2003.

[3] L. Zhao, K. O'Neill, and R. Diaz Brinton, "Selective estrogen receptor modulators (SERMs) for the brain: current status and remaining challenges for developing NeuroSERMs," Brain Research Reviews, vol. 49, no. 3, pp. 472-493, 2005.

[4] L. L. DonCarlos, I. Azcoitia, and L. M. Garcia-Segura, "Neuroprotective actions of selective estrogen receptor modulators," Psychoneuroendocrinology, vol. 34, supplement 1, pp. S113S122, 2009.

[5] M. A. Arevalo, M. Santos-Galindo, N. Lagunas, I. Azcoitia, and L. M. Garcia-Segura, "Selective estrogen receptor modulators as brain therapeutic agents," Journal of Molecular Endocrinology, vol. 46, no. 1, pp. R1-R9, 2011.

[6] K. M. Dhandapani and D. W. Brann, "Protective effects of estrogen and selective estrogen receptor modulators in the brain," Biology of Reproduction, vol. 67, no. 5, pp. 1379-1385, 2002.

[7] I. Ciriza, P. Carrero, I. Azcoitia, S. G. Lundeen, and L. M. Garcia-Segura, "Selective estrogen receptor modulators protect hippocampal neurons from kainic acid excitotoxicity: differences with the effect of estradiol," Journal of Neurobiology, vol. 61, no. 2, pp. 209-221, 2004.

[8] B. F. Bebo, B. Dehghani, S. Foster, A. Kurniawan, F. J. Lopez, and L. S. Sherman, "Treatment with selective estrogen receptor modulators regulates myelin specific T-cells and suppresses experimental autoimmune encephalomyelitis," GLIA, vol. 57, no. 7, pp. 777-790, 2009.

[9] L. Zhao, K. O'Neill, and R. D. Brinton, "Selective estrogen receptor modulators (SERMs) for the brain: current status and remaining challenges for developing NeuroSERMs," Brain Research Reviews, vol. 49, no. 3, pp. 472-493, 2005.

[10] L. Zhao, K. O’Neill, and R. D. Brinton, "Estrogenic agonist activity of ICI 182,780 (Faslodex) in hippocampal neurons: implications for basic science understanding of estrogen signaling and development of estrogen modulators with a dual therapeutic profile," Journal of Pharmacology and Experimental Therapeutics, vol. 319, no. 3, pp. 1124-1132, 2006.

[11] S. Benvenuti, P. Luciani, G. B. Vannelli et al., "Estrogen and selective estrogen receptor modulators exert neuroprotective effects and stimulate the expression of Selective Alzheimer's Disease Indicator-1, a recently discovered antiapoptotic gene, in human neuroblast long-term cell cultures," Journal of Clinical Endocrinology and Metabolism, vol. 90, no. 3, pp. 1775-1782, 2005.
[12] E. Biewenga, L. Cabell, and T. Audesirk, "Estradiol and raloxifene protect cultured SN4741 neurons against oxidative stress," Neuroscience Letters, vol. 373, no. 3, pp. 179-183, 2005.

[13] M. Bourque, B. Liu, D. E. Dluzen, and T. Di Paolo, "Tamoxifen protects male mice nigrostriatal dopamine against methamphetamine-induced toxicity," Biochemical Pharmacology, vol. 74, no. 9, pp. 1413-1423, 2007.

[14] S. Callier, M. Morissette, M. Grandbois, D. Pelaprat, and T. Di Paolo, "Neuroprotective properties of $17 \beta$-estradiol, progesterone, and raloxifene in MPTP C57Bl/6 mice," Synapse, vol. 41, no. 2, pp. 131-138, 2001.

[15] B. Du, M. Ohmichi, K. Takahashi et al., "Both estrogen and raloxifene protect against $\beta$-amyloid-induced neurotoxicity in estrogen receptor $\alpha$-transfected PC12 cells by activation of telomerase activity via Akt cascade," Journal of Endocrinology, vol. 183, no. 3, pp. 605-615, 2004.

[16] Y. Feng, J. D. Fratkins, and M. H. LeBlanc, "Treatment with tamoxifen reduces hypoxic-ischemic brain injury in neonatal rats," European Journal of Pharmacology, vol. 484, no. 1, pp. 65-74, 2004.

[17] M. Grandbois, M. Morissette, S. Callier, and T. Di Paolo, "Ovarian steroids and raloxifene prevent MPTP-induced dopamine depletion in mice," NeuroReport, vol. 11, no. 2, pp. 343-346, 2000.

[18] H. K. Kimelberg, "Tamoxifen as a powerful neuroprotectant in experimental stroke and implications for human stroke therapy," Recent Patents on CNS Drug Discovery, vol. 3, no. 2, pp. 104-108, 2008.

[19] H. K. Kimelberg, Y. Jin, C. Charniga, and P. J. Feustel, "Neuroprotective activity of tamoxifen in permanent focal ischemia," Journal of Neurosurgery, vol. 99, no. 1, pp. 138-142, 2003.

[20] O. N. Kokiko, A. K. Murashov, and M. R. Hoane, "Administration of raloxifene reduces sensorimotor and working memory deficits following traumatic brain injury," Behavioural Brain Research, vol. 170, no. 2, pp. 233-240, 2006.

[21] E. S. Y. Lee, Z. Yin, D. Milatovic, H. Jiang, and M. Aschner, "Estrogen and tamoxifen protect against Mn-induced toxicity in rat cortical primary cultures of neurons and astrocytes," Toxicological Sciences, vol. 110, no. 1, pp. 156-167, 2009.

[22] E. S. Y. Lee, M. Sidoryk, H. Jiang, Z. Yin, and M. Aschner, "Estrogen and tamoxifen reverse manganese-induced glutamate transporter impairment in astrocytes," Journal of Neurochemistry, vol. 110, no. 2, pp. 530-544, 2009.

[23] D. L. Lei, J. M. Long, J. Hengemihle et al., "Effects of estrogen and raloxifene on neuroglia number and morphology in the hippocampus of aged female mice," Neuroscience, vol. 121, no. 3, pp. 659-666, 2003.

[24] R. McMurray, R. Islamov, and A. K. Murashov, "Raloxifene analog LY117018 enhances the regeneration of sciatic nerve in ovariectomized female mice," Brain Research, vol. 980, no. 1, pp. 140-145, 2003.

[25] S. H. Mehta, K. M. Dhandapani, L. M. De Sevilla, R. C. Webb, V. B. Mahesh, and D. W. Brann, "Tamoxifen, a selective estrogen receptor modulator, reduces ischemic damage caused by middle cerebral artery occlusion in the ovariectomized female rat," Neuroendocrinology, vol. 77, no. 1, pp. 44-50, 2003.

[26] K. R. Mickley and D. E. Dluzen, "Dose-response effects of estrogen and tamoxifen upon methamphetamine- induced behavioral responses and neurotoxicity of the nigrostriatal dopaminergic system in female mice," Neuroendocrinology, vol. 79, no. 6, pp. 305-316, 2004. 
[27] M. Morissette, S. A. Sweidi, S. Callier, and T. Di Paolo, "Estrogen and SERM neuroprotection in animal models of Parkinson's disease," Molecular and Cellular Endocrinology, vol. 290, no. 1-2, pp. 60-69, 2008.

[28] M. I. Rossberg, S. J. Murphy, R. J. Traystman, and P. D. Hurn, "LY353381.HCl, a selective estrogen receptor modulator, and experimental stroke," Stroke, vol. 31, no. 12, pp. 3041-3046, 2000.

[29] H. Zhang, M. Xie, G. P. Schools et al., "Tamoxifen mediated estrogen receptor activation protects against early impairment of hippocampal neuron excitability in an oxygen/glucose deprivation brain slice ischemia model," Brain Research, vol. 1247, pp. 196-211, 2009.

[30] P. S. Green, S. H. Yang, K. R. Nilsson, A. S. Kumar, D. F. Covey, and J. W. Simpkins, "The nonfeminizing enantiomer of $17 \beta$ estradiol exerts protective effects in neuronal cultures and a rat model of cerebral ischemia," Endocrinology, vol. 142, no. 1, pp. 400-406, 2001.

[31] M. E. Jung, A. M. Wilson, and J. W. Simpkins, "A nonfeminizing estrogen analog protects against ethanol withdrawal toxicity in immortalized hippocampal cells," Journal of Pharmacology and Experimental Therapeutics, vol. 319, no. 2, pp. 543-550, 2006.

[32] R. Liu, S. H. Yang, E. Perez et al., "Neuroprotective effects of a novel non-receptor-binding estrogen analogue: in vitro and in vivo analysis," Stroke, vol. 33, no. 10, pp. 2485-2491, 2002.

[33] J. W. Simpkins, Y. Wen, E. Perez, S. Yang, and X. Wang, "Role of nonfeminizing estrogens in brain protection from cerebral ischemia: an animal model of Alzheimer's disease neuropathology," Annals of the New York Academy of Sciences, vol. 1052, pp. 233-242, 2005.

[34] X. Wang, J. A. Dykens, E. Perez et al., "Neuroprotective effects of $17 \beta$-estradiol and nonfeminizing estrogens against $\mathrm{H} 2 \mathrm{O} 2$ toxicity in human neuroblastoma SK-N-SH cells," Molecular Pharmacology, vol. 70, no. 1, pp. 395-404, 2006.

[35] I. Azcoitia, A. Moreno, P. Carrero, S. Palacios, and L. M. Garcia-Segura, "Neuroprotective effects of soy phytoestrogens in the rat brain," Gynecological Endocrinology, vol. 22, no. 2, pp. 63-69, 2006.

[36] D. A. Schreihofer and L. Redmond, "Soy phytoestrogens are neuroprotective against stroke-like injury in vitro," Neuroscience, vol. 158, no. 2, pp. 602-609, 2009.

[37] D. L. Lei, J. M. Long, J. Hengemihle et al., "Effects of estrogen and raloxifene on neuroglia number and morphology in the hippocampus of aged female mice," Neuroscience, vol. 121, no. 3, pp. 659-666, 2003.

[38] S. Tapia-Gonzalez, P. Carrero, O. Pernia, L. M. GarciaSegura, and Y. Diz-Chaves, "Selective oestrogen receptor (ER) modulators reduce microglia reactivity in vivo after peripheral inflammation: potential role of microglial ERs," Journal of Endocrinology, vol. 198, no. 1, pp. 219-230, 2008.

[39] M. Cerciat, M. Unkila, L. M. Garcia-Segura, and M. A. Arevalo, "Selective estrogen receptor modulators decrease the production of interleukin- 6 and interferon- $\gamma$-inducible protein-10 by astrocytes exposed to inflammatory challenge in vitro," GLIA, vol. 58, no. 1, pp. 93-102, 2010.

[40] T. Suuronen, T. Nuutinen, J. Huuskonen, J. Ojala, A. Thornell, and A. Salminen, "Anti-inflammatory effect of selective estrogen receptor modulators (SERMs) in microglial cells," Inflammation Research, vol. 54, no. 5, pp. 194-203, 2005.

[41] G. Barreto, M. Santos-Galindo, Y. Diz-Chaves et al., "Selective estrogen receptor modulators decrease reactive astrogliosis in the injured brain: effects of aging and prolonged depletion of ovarian hormones," Endocrinology, vol. 150, no. 11, pp. 50105015, 2009.

[42] J. L. Liu, D. S. Tian, Z. W. Li et al., "Tamoxifen alleviates irradiation-induced brain injury by attenuating microglial inflammatory response in vitro and in vivo," Brain Research, vol. 1316, pp. 101-111, 2010.

[43] D. S. Tian, J. L. Liu, M. J. Xie et al., "Tamoxifen attenuates inflammatory-mediated damage and improves functional outcome after spinal cord injury in rats," Journal of Neurochemistry, vol. 109, no. 6, pp. 1658-1667, 2009.

[44] J. Nilsen, G. Mor, and F. Naftolin, "Raloxifene induces neurite outgrowth in estrogen receptor positive PC12 cells," Menopause, vol. 5, no. 4, pp. 211-216, 1998.

[45] K. O'Neill, S. Chen, and R. D. Brinton, "Impact of the selective estrogen receptor modulator, tamoxifen, on neuronal outgrowth and survival following toxic insults associated with aging and Alzheimer's disease," Experimental Neurology, vol. 188, no. 2, pp. 268-278, 2004.

[46] E. Gould, C. S. Woolley, M. Frankfurt, and B. S. McEwen, "Gonadal steroids regulate dendritic spine density in hippocampal pyramidal cells in adulthood," Journal of Neuroscience, vol. 10, no. 4, pp. 1286-1291, 1990.

[47] C. S. Woolley and B. S. McEwen, "Roles of estradiol and progesterone in regulation of hippocampal dendritic spine density during the estrous cycle in the rat," Journal of Comparative Neurology, vol. 336, no. 2, pp. 293-306, 1993.

[48] B. S. McEwen and C. S. Woolley, "Estradiol and progesterone regulate neuronal structure and synaptic connectivity in adult as well as developing brain," Experimental Gerontology, vol. 29, no. 3-4, pp. 431-436, 1994.

[49] D. D. Murphy and M. Segal, "Regulation of dendritic spine density in cultured rat hippocampal neurons by steroid hormones," Journal of Neuroscience, vol. 16, no. 13, pp. 40594068, 1996.

[50] C. S. Woolley, "Estrogen-mediated structural and functional synaptic plasticity in the female rat hippocampus," Hormones and Behavior, vol. 34, no. 2, pp. 140-148, 1998.

[51] F. Liu, M. Day, L. C. Muñiz et al., "Activation of estrogen receptor- $\beta$ regulates hippocampal synaptic plasticity and improves memory," Nature Neuroscience, vol. 11, no. 3, pp. 334-343, 2008.

[52] K. Sharma, R. D. Mehra, P. Dhar, and U. Vij, "Chronic exposure to estrogen and tamoxifen regulates synaptophysin and phosphorylated cAMP response element-binding (CREB) protein expression in CA1 of ovariectomized rat hippocampus," Brain Research, vol. 1132, no. 1, pp. 10-19, 2007.

[53] X. Wu, M. A. Glinn, N. L. Ostrowski et al., "Raloxifene and estradiol benzoate both fully restore hippocampal choline acetyltransferase activity in ovariectomized rats," Brain Research, vol. 847, no. 1, pp. 98-104, 1999.

[54] M. Cyr, M. Landry, and T. Di Paolo, "Modulation by estrogenreceptor directed drugs of 5-hydroxytryptamine-2A receptors in rat brain," Neuropsychopharmacology, vol. 23, no. 1, pp. 69$78,2000$.

[55] M. G. Sánchez, M. Bourque, M. Morissette, and T. Di Paolo, "Steroids-dopamine interactions in the pathophysiology and treatment of cns disorders," CNS Neuroscience and Therapeutics, vol. 16, no. 3, pp. e43-e71, 2010.

[56] L. J. Smith, J. A. Henderson, C. W. Abell, and C. L. Bethea, "Effects of ovarian steroids and raloxifene on proteins that synthesize, transport, and degrade serotonin in the raphe region of macaques," Neuropsychopharmacology, vol. 29, no. 11, pp. 2035-2045, 2004. 
[57] N. Lagunas, I. Calmarza-Font, D. Grassi, and L. M. GarciaSegura, "Estrogen receptor ligands counteract cognitive deficits caused by androgen deprivation in male rats," Hormones and Behavior, vol. 59, no. 4, pp. 581-584, 2011.

[58] I. Gonzalez-Burgos, G. Tapia-Arizmendi, and A. Feria-Velasco, "Golgi method without osmium tetroxide for the study of the central nervous system," Biotechnic and Histochemistry, vol. 67, no. 5, pp. 288-296, 1992.

[59] A. Peters and I. R. Kaiserman-Abramof, "The small pyramidal neuron of the rat cerebral cortex-the synapses upon dendritic spines," Zeitschrift für Zellforschung und Mikroskopische Anatomie, vol. 100, no. 4, pp. 487-506, 1969.

[60] L. Tarelo-Acuña, E. Olvera-Cortés, and I. González-Burgos, "Prenatal and postnatal exposure to ethanol induces changes in the shape of the dendritic spines from hippocampal CA1 pyramidal neurons of the rat," Neuroscience Letters, vol. 286, no. 1, pp. 13-16, 2000.

[61] I. González-Burgos, M. Alejandre-Gómez, and M. Cervantes, "Spine-type densities of hippocampal CA1 neurons vary in proestrus and estrus rats," Neuroscience Letters, vol. 379, no. 1, pp. 52-54, 2005.

[62] B. Leuner and T. J. Shors, "New spines, new memories," Molecular Neurobiology, vol. 29, no. 2, pp. 117-130, 2004.

[63] S. Hugel, M. Abegg, V. De Paola, P. Caroni, B. H. Gähwiler, and R. A. McKinney, "Dendritic spine morphology determines membrane-associated protein exchange between dendritic shafts and spine heads," Cerebral Cortex, vol. 19, no. 3, pp. 697702, 2009.

[64] M. Matsuzaki, G. C. R. Ellis-Davies, T. Nemoto, Y. Miyashita, M. Iino, and H. Kasai, "Dendritic spine geometry is critical for AMPA receptor expression in hippocampal CA1 pyramidal neurons," Nature Neuroscience, vol. 4, no. 11, pp. 1086-1092, 2001.

[65] O. Ganeshina, R. W. Berry, R. S. Petralia, D. A. Nicholson, and Y. Geinisman, "Synapses with a segmented, completely partitioned postsynaptic density express more AMPA receptors than other axospinous synaptic junctions," Neuroscience, vol. 125, no. 3, pp. 615-623, 2004.

[66] M. C. Ashby, S. R. Maier, A. Nishimune, and J. M. Henley, "Lateral diffusion drives constitutive exchange of AMPA receptors at dendritic spines and is regulated by spine morphology," Journal of Neuroscience, vol. 26, no. 26, pp. 7046-7055, 2006.

[67] E. A. Nimchinsky, R. Yasuda, T. G. Oertner, and K. Svoboda, "The number of glutamate receptors opened by synaptic stimulation in single hippocampal spines," Journal of Neuroscience, vol. 24, no. 8, pp. 2054-2064, 2004.

[68] A. Majewska, A. Tashiro, and R. Yuste, "Regulation of spine calcium dynamics by rapid spine motility," Journal of Neuroscience, vol. 20, no. 22, pp. 8262-8268, 2000.

[69] R. Yuste, A. Majewska, and K. Holthoff, "From form to function: calcium compartmentalization in dendritic spines," Nature Neuroscience, vol. 3, no. 7, pp. 653-659, 2000.

[70] Y. Hayashi and A. K. Majewska, "Dendritic spine geometry: functional implication and regulation," Neuron, vol. 46, no. 4, pp. 529-532, 2005.

[71] J. Noguchi, M. Matsuzaki, G. C. R. Ellis-Davies, and H. Kasai, "Spine-neck geometry determines NMDA receptordependent $\mathrm{Ca}^{2+}$ signaling in dendrites," Neuron, vol. 46, no. 4, pp. 609-622, 2005.

[72] H. Schmidt and J. Eilers, "Spine neck geometry determines spino-dendritic cross-talk in the presence of mobile endogenous calcium binding proteins," Journal of Computational Neuroscience, vol. 27, no. 2, pp. 229-243, 2009.
[73] R. Araya, J. Jiang, K. B. Eisenthal, and R. Yuste, "The spine neck filters membrane potentials," Proceedings of the National Academy of Sciences of the United States of America, vol. 103, no. 47, pp. 17961-17966, 2006.

[74] C. Koch, A. Zador, and T. H. Brown, "Dendritic spines: convergence of theory and experiment," Science, vol. 256, no. 5059, pp. 973-974, 1992.

[75] E. Korkotian and M. Segal, "Structure-function relations in dendritic spines: is size important?" Hippocampus, vol. 10, no. 5, pp. 587-595, 2000.

[76] M. I. Pérez-Vega, A. Feria-Velasco, and I. González-Burgos, "Prefrontocortical serotonin depletion results in plastic changes of prefrontocortical pyramidal neurons, underlying a greater efficiency of short-term memory," Brain Research Bulletin, vol. 53, no. 3, pp. 291-300, 2000.

[77] K. M. Harris, J. C. Fiala, and L. Ostroff, "Structural changes at dendritic spine synapses during long-term potentiation," Philosophical Transactions of the Royal Society B, vol. 358, no. 1432, pp. 745-748, 2003.

[78] J. Bourne and K. M. Harris, "Do thin spines learn to be mushroom spines that remember?" Current Opinion in Neurobiology, vol. 17, no. 3, pp. 381-386, 2007.

[79] I. González-Burgos, "Dendritic spine plasticity and learning/memory processes: theory, evidence and perspectives," in Dendritic Spines: Biochemistry, Modeling and Properties, L. R. Baylog, Ed., pp. 163-186, Nova Science Publishers, Huntington, NY, USA, 2009.

[80] K. M. Harris, F. E. Jensen, and B. Tsao, "Three-dimensional structure of dendritic spines and synapses in rat hippocampus (CA 1) at postnatal day 15 and adult ages: implications for the maturation of synaptic physiology and long-term potentiation," Journal of Neuroscience, vol. 12, no. 7, pp. 26852705, 1992.

[81] H. Kasai, M. Matsuzaki, J. Noguchi, N. Yasumatsu, and H. Nakahara, "Structure-stability-function relationships of dendritic spines," Trends in Neurosciences, vol. 26, no. 7, pp. 360-368, 2003.

[82] M. Matsuzaki, N. Honkura, G. C. R. Ellis-Davies, and H. Kasai, "Structural basis of long-term potentiation in single dendritic spines," Nature, vol. 429, no. 6993, pp. 761-766, 2004.

[83] V. Birzniece, A. Sata, S. Sutanto, and K. K. Y. Ho, "Neuroendocrine regulation of growth hormone and androgen axes by selective estrogen receptor modulators in healthy men," Journal of Clinical Endocrinology and Metabolism, vol. 95, no. 12, pp. 5443-5448, 2010.

[84] K. M. Webber, G. Perry, M. A. Smith, and G. Casadesus, "The contribution of luteinizing hormone to Alzheimer Disease pathogenesis," Clinical Medicine and Research, vol. 5, no. 3, pp. 177-183, 2007.

[85] G. Casadesus, K. M. Webber, C. S. Atwood et al., "Luteinizing hormone modulates cognition and amyloid- $\beta$ deposition in Alzheimer APP transgenic mice," Biochimica et Biophysica Acta, vol. 1762, no. 4, pp. 447-452, 2006. 

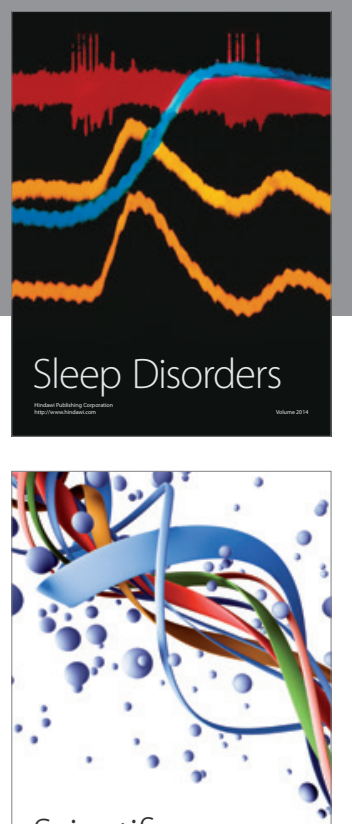

Scientifica
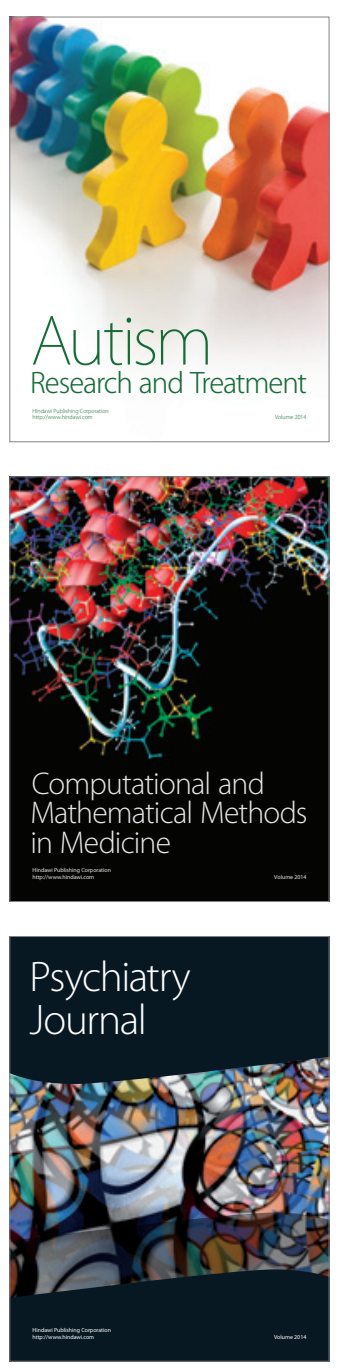
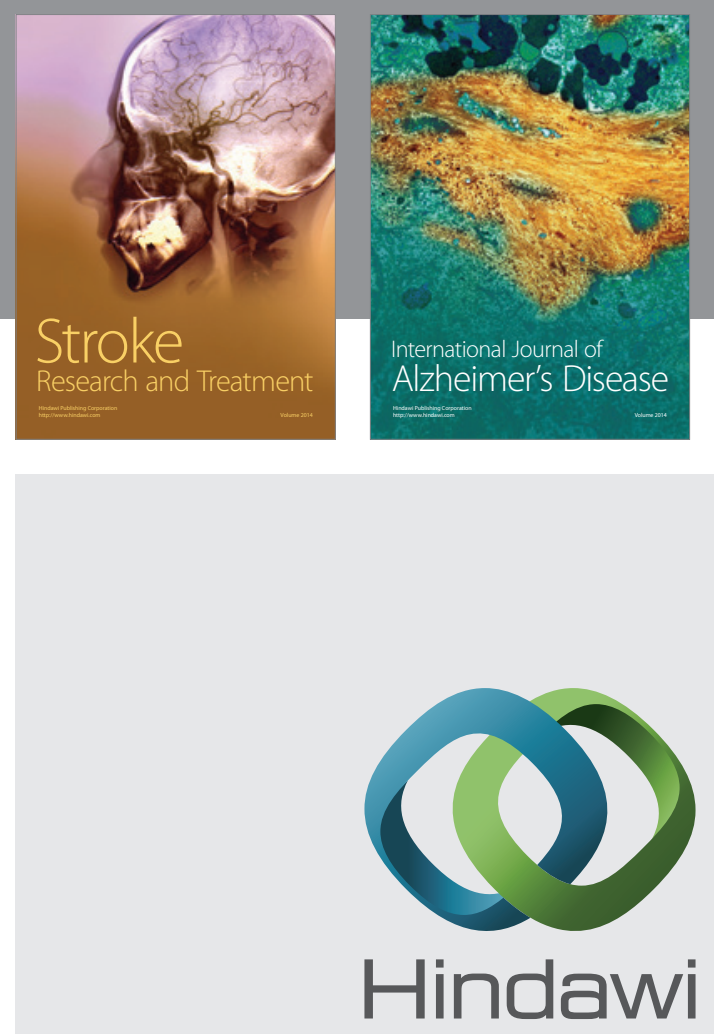

Submit your manuscripts at

http://www.hindawi.com
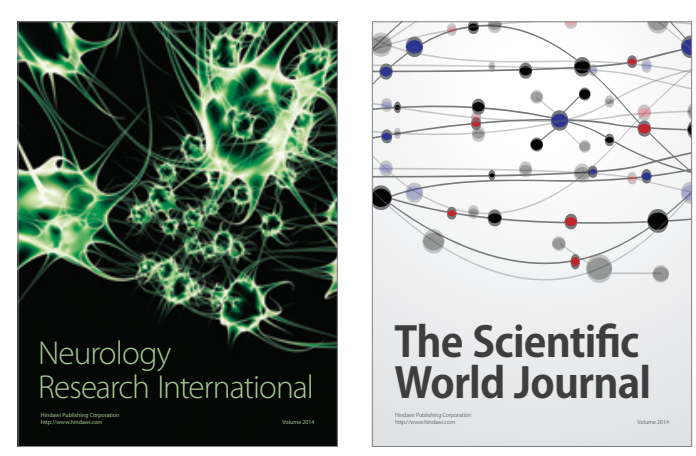

The Scientific World Journal

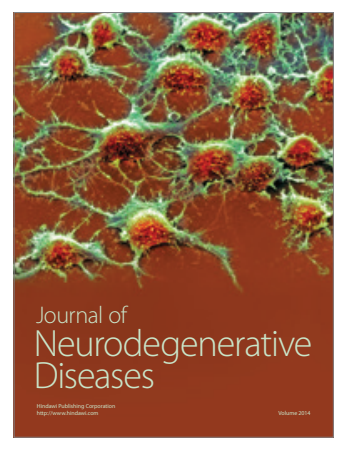

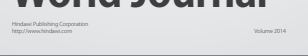

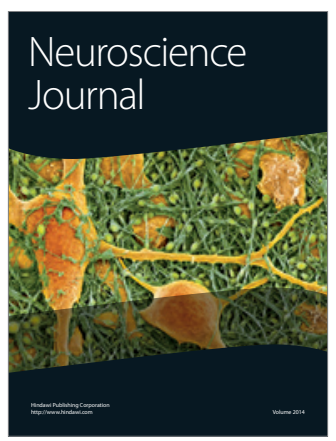

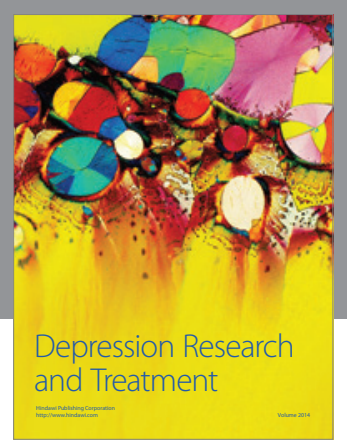
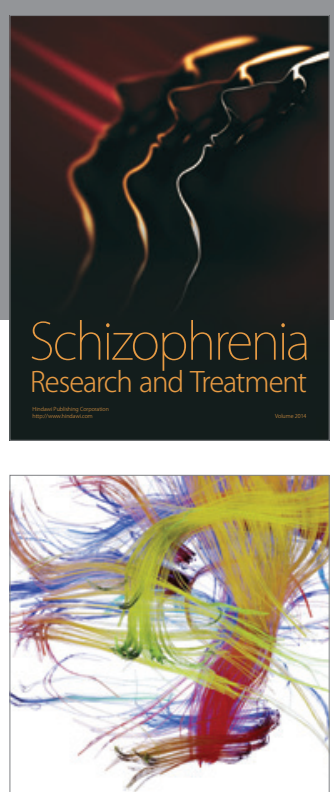

Brain Science

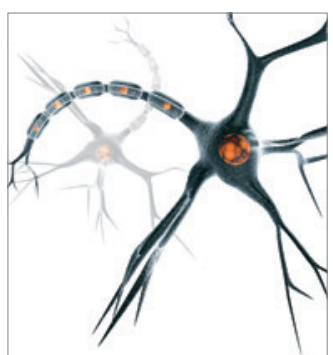

Neural Plasticity
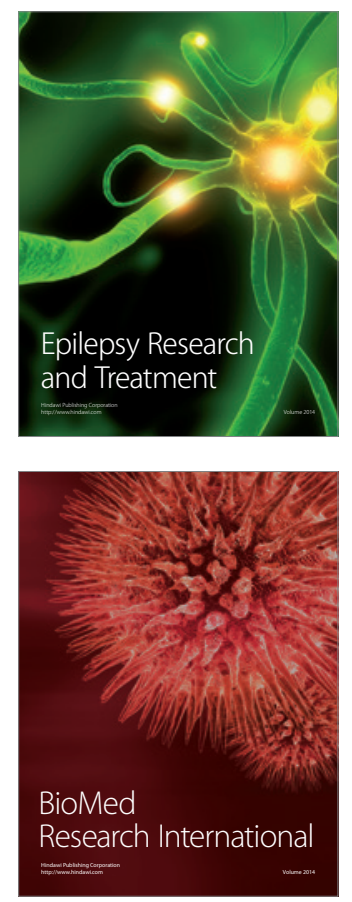

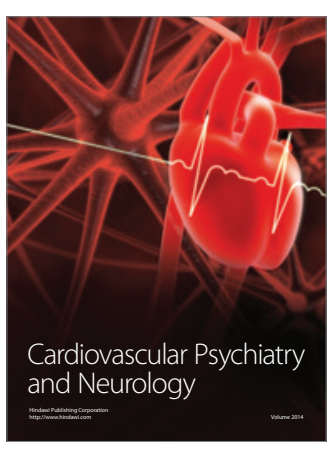

Parkinson's

Disease
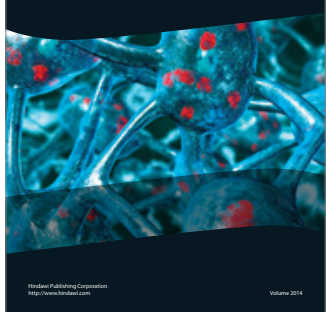